\title{
Adjustable ultraviolet-sensitive detectors based on amorphous silicon
}

\author{
Marko Topiča) \\ Faculty of Electrical Engineering, University of Ljubljana, Trzaska 25, SI-1000 Ljubljana, Slovenia \\ Helmut Stiebig, Mathias Krause, and Heribert Wagner \\ Institut fuer Photovoltaik, Forschungszentrum Juelich, D-52425 Juelich, Germany
}

(Received 19 December 2000; accepted for publication 21 February 2001)

\begin{abstract}
Thin-film detectors made of hydrogenated amorphous silicon $(a-\mathrm{Si}: \mathrm{H})$ and amorphous silicon carbide $(a-\mathrm{SiC}: \mathrm{H})$ with adjustable sensitivity in the ultraviolet (UV) spectrum were developed. Thin $P I N$ diodes deposited on glass substrates in $N-I-P$ layer sequence with a total thickness of down to $33 \mathrm{~nm}$ and a semitransparent Ag front contact were fabricated. The optimized diodes with a 10 $\mathrm{nm} \mathrm{Ag}$ contact exhibit spectral response values above $80 \mathrm{~mA} / \mathrm{W}$ in the wavelength range from 295 to $395 \mathrm{~nm}$ with a maximum of $91 \mathrm{~mA} / \mathrm{W}$ at $320 \mathrm{~nm}$. For longer wavelengths, the spectral response drops by $50 \%$ at $450 \mathrm{~nm}$. Increasing the thickness of the $\mathrm{Ag}$ front contact leads to a narrowing of the spectral response at around $320 \mathrm{~nm}$, which allows the adjustment from a broad UV to a selective UV-B-sensitive detector. (C) 2001 American Institute of Physics. [DOI: 10.1063/1.1365948]
\end{abstract}

Hydrogenated amorphous silicon $(a-\mathrm{Si}: \mathrm{H})$ and its alloys $(a-\mathrm{SiC}: \mathrm{H}, a-\mathrm{SiGe}: \mathrm{H})$ exhibit high photosensitivity in the wide spectral range from ultraviolet (UV) to infrared. Lowcost fabrication and low-temperature deposition over large areas by plasma-enhanced chemical-vapor deposition (PECVD) make them attractive for realization of large-area devices and large-area arrays with arbitrary shape and even onto flexible substrates. ${ }^{1} a$-Si:H-based photodetectors with enhanced sensitivity in the near UV, down to the wavelength $(\lambda)$ of $350 \mathrm{~nm},{ }^{2,3}$ or with sensitivity in vacuum UV $(\lambda$ $<200 \mathrm{~nm}),{ }^{4}$ have been reported, but no detector so far has covered the range of UV-A and UV-B. In this spectral range, the development of a low-cost detector is of great interest for monitoring of skin exposure to harmful UV radiation. Reference 2 dealt with devices in superstrate configuration, while Ref. 3 investigated devices in substrate configuration. Both of them showed only a weak suppression of the responsivity in the visible range. The device in Ref. 4 exhibited a too strong suppression of the spectral response for wavelengths above $300 \mathrm{~nm}$ since it was optimized for application in the vacuum UV range.

In this letter, we demonstrate thin-film diodes made of $a-\mathrm{SiC}: \mathrm{H} / a-\mathrm{Si}: \mathrm{H}$ exhibiting good sensitivity in the UV and suppressed sensitivity in the visible spectrum range. Its selectivity and/or sensitivity can be adjusted with either thickness variation of both, front contact layer and semiconducting amorphous layers, or variation of optical properties of active layers. In this letter, the band gap of the used layers was kept constant.

Figure 1 shows the cross section of a detector in sandwich configuration. On a Corning glass substrate a transparent conductive oxide ( $\mathrm{ZnO}: \mathrm{Al}$ ) layer ${ }^{5}$ was sputtered. $\mathrm{ZnO}: \mathrm{Al}$ was used as the back contact, since a bad reflector/good transmitter of the visible light is desired to suppress the detector's sensitivity in the visible-light spectrum. The amorphous-silicon-based layers were deposited in a multichamber PECVD system at a substrate temperature of

${ }^{a)}$ Electronic mail: marko.topic@fe.uni-lj.si
$200{ }^{\circ} \mathrm{C}$, a pressure between 500 and 1000 mTorr, and a radio-frequency $(13.56 \mathrm{MHz})$ power density of $40-52$ $\mathrm{mW} / \mathrm{cm}^{2}$. $P I N$ diodes were deposited in a $N-I-P$ layer sequence. $N$ - and $P$-type doped layers were realized by adding phosphine and trimethyl boron in the deposition gas mixture of $\mathrm{SiH}_{4}$ and $\mathrm{H}_{2}$, respectively. $P$ and $I$ layers were made of $a-\mathrm{SiC}: \mathrm{H}$ by adding methane in the deposition gas mixture. For the optical band gap $E_{\text {opt }}$ of individual layers (as indicated in Fig. 1), we used $E_{3.5}$, i.e., the energy where the absorption coefficient amounts to $10^{3.5} \mathrm{~cm}^{-1}$. The values were taken from optical reflection and transmission measurements, using separately prepared samples. As a front contact, a thin semitransparent metal (Ag) layer of $10 \mathrm{~nm}$ was evaporated. The total area of the device was $1 \mathrm{~cm}^{2}$.

The spectral response (SR) and quantum efficiency (QE) of the detectors have been measured in air in the wavelength range 200-800 nm, using a photon flux of around $10^{14}$ photons $/\left(\mathrm{cm}^{2} \mathrm{~s}\right)$. The photocurrent of the detectors was measured by a lock-in technique.

Figure 2 shows the spectral response under zero bias for three PIN diodes (designated as samples A, B, and C) with different layer thicknesses (see Table I). Decreasing the

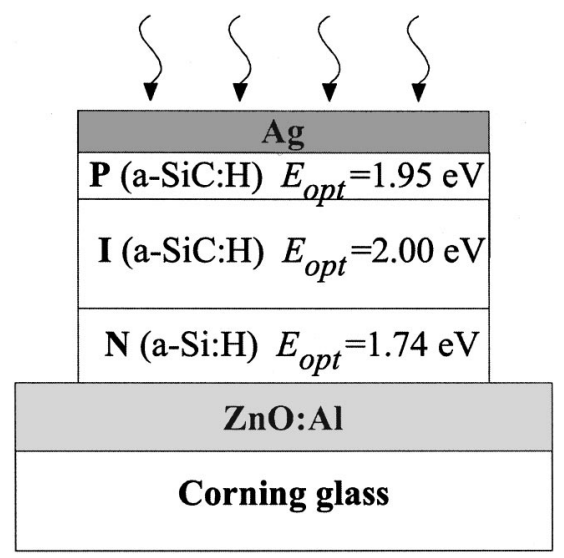

FIG. 1. Schematic view of $\mathrm{Ag} / P-I-N / \mathrm{ZnO}: \mathrm{Al}$ diodes. The material composition and the optical band-gap values are also indicated. 


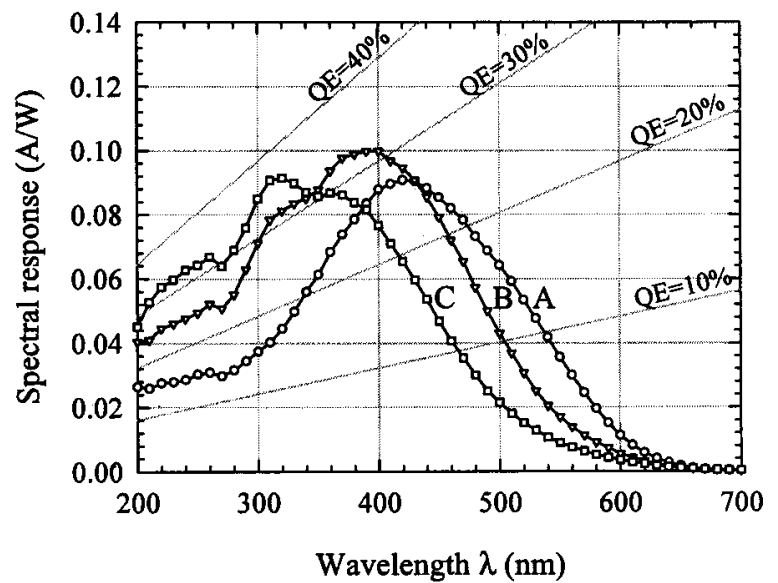

FIG. 2. Spectral response of three PIN diodes (samples A, B, and C) with different layer thicknesses (see Table I). Straight lines indicate quantumefficiency equilines.

$I$-layer thickness of the PIN diode from $50 \mathrm{~nm}$ (sample A) to $30 \mathrm{~nm}$ (sample B), the peak and also the long-wavelength cutoff shift toward the near-UV region. Additionally, for sample B a significant improvement of sensitivity in the UV occurs due to the decrease of $P$-layer thickness. The reduction of $P$-layer thickness enables that more photons reach the $I$ layer, where the collection efficiency of the photogenerated carrier is much higher. Ideally, the $P$ layer should be as thin as possible, but still thick enough to ensure sufficient charge for building up the electric field across the PIN diode. Reduction of the $P$ layer to only $3 \mathrm{~nm}$ and the $I$ layer to only 10 $\mathrm{nm}$ (sample C) results in further improvement of the spectral response in the UV range and its additional suppression in the visible range. This thin diode (sample $\mathrm{C}$ ) with a total thickness of $33 \mathrm{~nm}$ exhibits a spectral response above 80 $\mathrm{mA} / \mathrm{W}$ in the wavelength range from 295 to $395 \mathrm{~nm}$ with a maximum of $91 \mathrm{~mA} / \mathrm{W}$ at $\lambda=320 \mathrm{~nm}$. A $50 \%$ drop off from the maximum for longer wavelengths occurs at $450 \mathrm{~nm}$. From QE equilines in Fig. 2 we can see that this device exhibits QE values of over 30\% almost in the whole nonvacuum UV range, i.e., from 200 to $360 \mathrm{~nm}$, with the maximum of $36.3 \%$ at $310 \mathrm{~nm}$. These are excellent values for $a$-Si:H-based detectors in substrate configuration.

By decreasing the thickness of the PIN diodes (already below $100 \mathrm{~nm}$ ), the yield of diodes with good performance is limited due to shunts, which hinder low reverse dark currents. ${ }^{6}$ According to scanning electron microscopy measurements, we suppose that the origin of the shunts are irregularities like holes and spikes, as well as contamination of the glass and the $\mathrm{ZnO}: \mathrm{Al}$ substrate. As-grown $\mathrm{ZnO}: \mathrm{Al}$ layers are flat, exhibiting a $\delta_{\text {rms }}$ roughness of around $7 \mathrm{~nm}$ measured by atomic-force microscopy. Under optimized sputtering and cleaning conditions, a yield of around 50\% is

TABLE I. Layer thicknesses for different samples.

\begin{tabular}{lcccc}
\hline \hline Thickness & $\begin{array}{c}\text { ZnO:Al } \\
(\mathrm{nm})\end{array}$ & $\begin{array}{c}N \\
(\mathrm{~nm})\end{array}$ & $\begin{array}{c}I \\
(\mathrm{~nm})\end{array}$ & $\begin{array}{c}P \\
(\mathrm{~nm})\end{array}$ \\
\hline Sample A & 80 & 10 & 50 & 10 \\
Sample B & 80 & 10 & 30 & 5 \\
Sample C & 80 & 20 & 10 & 3 \\
\hline \hline
\end{tabular}

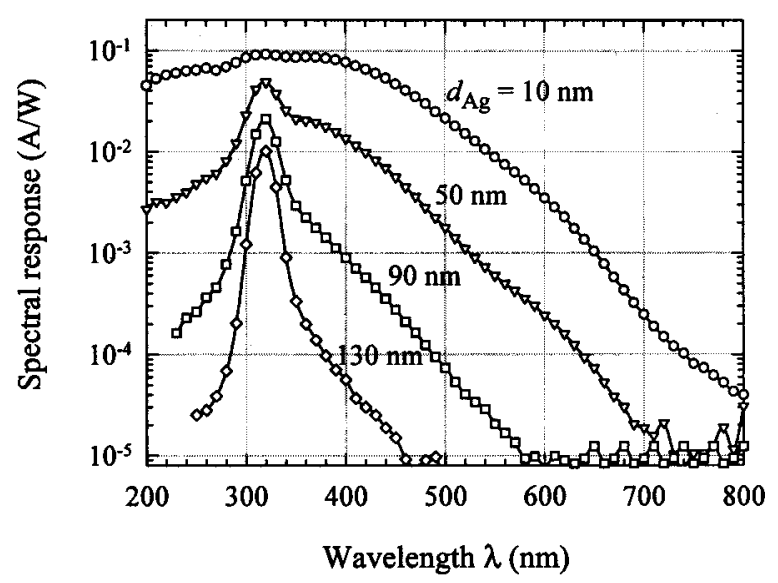

FIG. 3. Spectral response of the PIN diode (sample C) with a semitransparent Ag front contact of different thicknesses.

reached. Hence, for all samples (A-C) dark current densities below $10^{-9} \mathrm{~A} / \mathrm{cm}^{2}$ are achieved at $100 \mathrm{mV}$ reverse bias.

Since the absorption coefficient of Ag exhibits a local minimum at the wavelength of $320 \mathrm{~nm},{ }^{7}$ this property can be utilized for a selective UV detector. Therefore, we have investigated the effect of the thickness of the semitransparent front contact on the device behavior of our 33-nm-thick PIN diode (sample C). We varied the thickness of the Ag front contact from the initial $10 \mathrm{~nm}$ to $130 \mathrm{~nm}$ by three successive depositions of $40 \mathrm{~nm} \mathrm{Ag}$ per run. Figure 3 shows in a $\log$ scale of response the shrinking of the spectral response with increasing $\mathrm{Ag}$ front-contact thickness. In this way, its full width at half magnitude can be varied from $250 \mathrm{~nm}$ down to $20 \mathrm{~nm}$ (see Table II), while the maximum of the spectral response at $\lambda=320 \mathrm{~nm}$ loses less than one order of magnitude (only 90\%).

In summary, we have realized amorphous-silicon-based detectors with adjustable sensitivity in the ultraviolet spectrum and with suppressed sensitivity in the visible range. Very thin PIN diodes deposited in a $N-I-P$ sequence exhibit low reverse current densities. The best device performance was achieved with a 33-nm-thick PIN diode having a maximum spectral response of $91 \mathrm{~mA} / \mathrm{W}$ at $\lambda=320 \mathrm{~nm}$. Adjustable selectivity of the detectors with a peak at $\lambda$ $=320 \mathrm{~nm}$ was achieved by varying the thickness of the $\mathrm{Ag}$ front semitransparent contact. Such an approach allows the variation of the spectral sensitivity from a broad UV to a selective UV-B spectrum.

The authors thank E. Bunte and F. Smole for helpful discussions and A. Lambertz, W. Reetz, and H. Siekmann for technical assistance. One of the authors (M.T.) acknowledges the Alexander von Humboldt Foundation for a fellowship.

TABLE II. Effect of Ag front-contact-thickness variation on the maximum spectral response value and selectivity [full width at half magnitude (FWHM)] of sample C.

\begin{tabular}{lrrrr}
\hline \hline Ag thickness $(\mathrm{nm})$ & 10 & 50 & 90 & 130 \\
$\mathrm{SR}_{\max }(\mathrm{mA} / \mathrm{W})^{\mathrm{a}}$ & 91 & 49 & 21 & 10 \\
$\mathrm{FWHM}(\mathrm{nm})$ & 250 & 43 & 32 & 21 \\
\hline \hline
\end{tabular}

${ }^{\mathrm{a}}$ At $\lambda=320 \mathrm{~nm}$.

Downloaded 15 Dec 2006 to 134.94.122.39. Redistribution subject to AIP license or copyright, see http://apl.aip.org/apl/copyright.jsp 
${ }^{1}$ R. A. Street, Hydrogenated Amorphous Silicon (Cambridge University, Cambridge, UK, 1991).

${ }^{2}$ Y. K. Fang, S.-B. Hwang, K.-H. Chen, C.-R. Liu, M.-J. Tsai, and L.-C. Kuo, IEEE Trans. Electron Devices ED-39, 292 (1992).

${ }^{3}$ F. Mütze, K. Seibel, B. Schneider, M. Hillebrand, F. Blecher, T. Lule, H. Keller, P. Rieve, M. Wagner, and M. Boehm, in Amorphous Silicon Technology, edited by H. M. Branz, R. W. Collins, H. Okamoto, S. Guha, and R. Schropp (Materials Research Society, Warrendale, PA, 1999), Vol. 557 , p. 815.
${ }^{4}$ G. de Cesare, F. Irrera, F. Palma, and M. Tucci, Appl. Phys. Lett. 67, 335 (1995).

${ }^{5}$ A. Loeffl, S. Wieder, B. Rech, O. Kluth, C. Beneking, and H. Wagner, in Proceedings of the 14th European Photovoltaic Solar Energy Conference, edited by H. A. Ossenbrink, P. Helm, and H. Ehmann (Stephens, Bedford, 1997), p. 2089.

${ }^{6}$ M. Topič, H. Stiebig, D. Knipp, and F. Smole, IEEE Trans. Electron Devices ED-46, 1839 (1999).

${ }^{7}$ K. S. Gibson, Natl. Bur. Stand. Circ. (U. S.) 484, 1 (1949). 